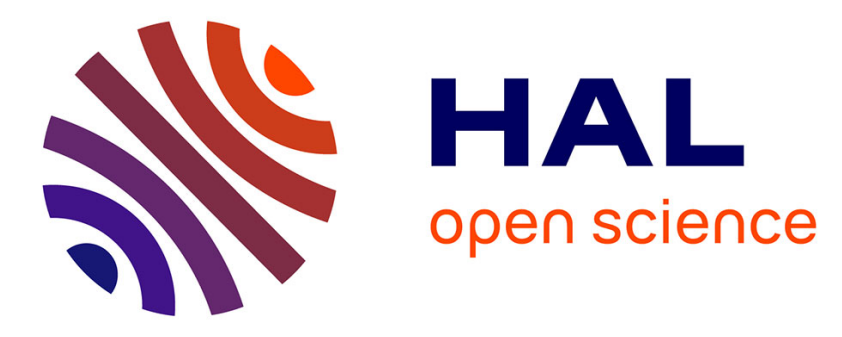

\title{
Flexibility of Class E HPA for Cognitive Multi-Radio Architecture
}

\author{
Antoine Diet, Fabien Robert, Martha Suarez, Vaclav Valenta, Luis Montes, \\ Christian Ripoll, Martine Villegas, Genevieve Baudoin
}

\section{- To cite this version:}

Antoine Diet, Fabien Robert, Martha Suarez, Vaclav Valenta, Luis Montes, et al.. Flexibility of Class E HPA for Cognitive Multi-Radio Architecture. The 19th Annual IEEE International Symposium on Personal, Indoor and Mobile Radio, Sep 2008, Cannes, France. pp.ISBN: 978-1-4244-2644-7. hal00447424

\section{HAL Id: hal-00447424 \\ https://hal.science/hal-00447424}

Submitted on 14 Jan 2012

HAL is a multi-disciplinary open access archive for the deposit and dissemination of scientific research documents, whether they are published or not. The documents may come from teaching and research institutions in France or abroad, or from public or private research centers.
L'archive ouverte pluridisciplinaire HAL, est destinée au dépôt et à la diffusion de documents scientifiques de niveau recherche, publiés ou non, émanant des établissements d'enseignement et de recherche français ou étrangers, des laboratoires publics ou privés. 


\title{
Flexibility of Class E HPA for Cognitive Multi-Radio Architecture
}

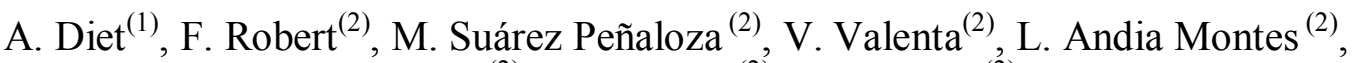 \\ C. Ripoll ${ }^{(2)}$, M. Villegas ${ }^{(2)}$, G. Baudoin ${ }^{(2)}$
}

(1) Département de Recherche en Électromagnétisme (DRÉ),

Laboratoire des Signaux et Systèmes (L2S, UMR 8506 Université Paris-Sud-11, CNRS, Supélec).

Supélec, 3 rue Joliot Curie, plateau du Moulon F-91192 Gif sur Yvette, France. antoine.diet@lss.supelec.fr

(2) Groupe ESIEE, Equipe Système de Communication et Micro-systèmes

(ESYCOM, EA 2552 Groupe ESIEE, CNAM, Université Paris-Est - Marne la Vallée)

Université Paris-Est - Marne la Vallée 77454 Champs sur Marne, France.

\{dieta, robertf, suarezm, valentav, andial, ripollc, villegam, baudoing\}@esiee.fr

\begin{abstract}
This paper consists in the analysis and simulation of two topologies of high efficiency power amplifier (HPA) in the context of the cognitive multi-radio architecture. More precisely, the goal is to study the possibility of front-end radio standards flexibility using a class E HPA. Two main topologies are studied, serial and parallel, and simulations under ADS software are performed in order to validate the proposed tuning of the HPA. Results encourage possibilities of providing efficient and constant power amplification from almost 1 to $5 \mathrm{GHz}$.
\end{abstract}

Keywords - Class E HPA, Cognitive Multi-radio.

\section{I - Cognitive Multi-RAdio STANDARDS}

Nowadays, wireless applications tend to higher data rate transfer for Wireless Local, Rural and Personal Area Networks (WLAN, WRAN, WPAN). Increasing number of standards brings cognitive radio and multi-radio principles to first plan. Coexistence of different wireless standards on a same device is necessary to satisfy users who want ubiquitous connection. This coexistence should not imply an increase on the size of the device or a reduction of its battery life. A universal transmitter architecture, able to generate all the different standard waveforms will be the best solution. This concept is known as multi-radio transmitter and implies flexibility of each stage of the communication chain. A classical digital communication wireless architecture in the case of a mobile phone is represented on figure 1 . The three principal parts can be clearly distinguished between (i) digital baseband, (ii) baseband analog/RF and (iii) RF front/backend. In this paper we will then focus on the RF front-end part consisting from driver/HPA to the antenna. We envisage a multi-radio architecture able to support existing standards between $900 \mathrm{MHz}$ and $6 \mathrm{GHz}$. Principal parameters to consider in a multi-radio signal are bandwidth, power dynamic range and envelope magnitude range (expressed by the Peak to Average Power Ratio - PAPR) which depend on the modulation type. From the mobile multi-radio transmitter point of view, key aspects are power efficiency and linearity. Moreover, transmitted signal is limited to the frequency band assigned by local regulation and must respect established limits of adjacent channel power ratio (ACPR) and power spectrum emission mask. If required, transmitter must be able to adjust its output power over a defined range. Multi-radio architecture should handle variations of above enounced parameters respecting standards requirements. Especially, allowed maximum output power in mobile terminals differs from a standard to another.

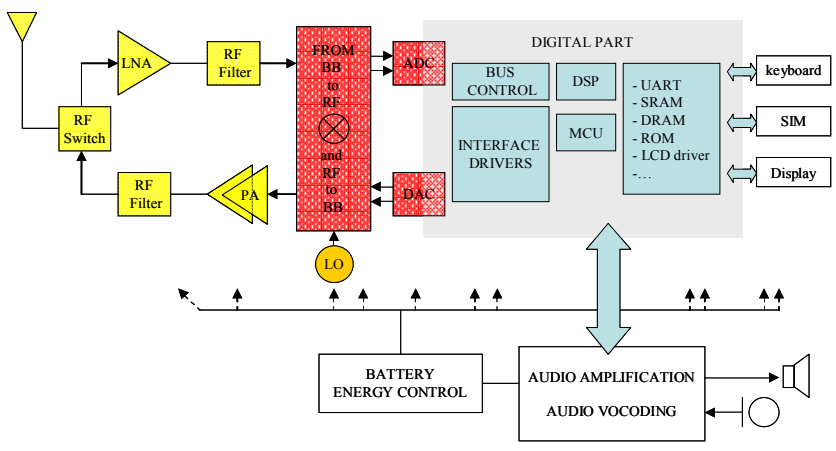

Figure 1 : typical wireless mobile phone architecture

In the difficult task to design a cognitive/multi-radio, the RF front-end part appears to be an entire flexible combination of RF blocs with high efficiency behaviour. The frequency of operation of this part is often subject to tradeoffs between efficiency, linearity and output power. The goal is here to find a highly efficient and frequency adaptable HPA to provide the needed tunability for the multi-radio. Second part will present directly switched mode class E HPA [1-2-3] where the flexibility is discussed. Power control and amplitude information can be restored with supply modulation [4-5] or using Sigma-Delta modulation [6]. The third part will summarized the frequency tuning possibilities in terms of efficiency, output power and linearity of such HPAs using a simple model of MESFET.

\section{II - THE FLEXIBLE HPA OF THE FRONT-END}

\section{A. Principle of the flexible HPA}

RF Power Amplifiers (PAs/HPAs) can be classified into two classes of operation [5] : (i) linear and quasi-linear low efficient polarised classes such as $\mathrm{A}, \mathrm{B}, \mathrm{AB}$ and $\mathrm{C}$ ones 
and switched high efficient but constant power driven classes such as D, S, E and F ones and their variations. Choosing a low efficient PA is avoided because interesting linearisation techniques of the architecture using switched PAs have been demonstrated since years, [5] is one example and the task here will not be to develop that point. Providing amplitude information is possible with a switched PA and the idea here is to focus on the frequency tuning possibility. The highest efficient PA is chosen for our study and the principle of our front-end co-design is illustrated on figure 2.

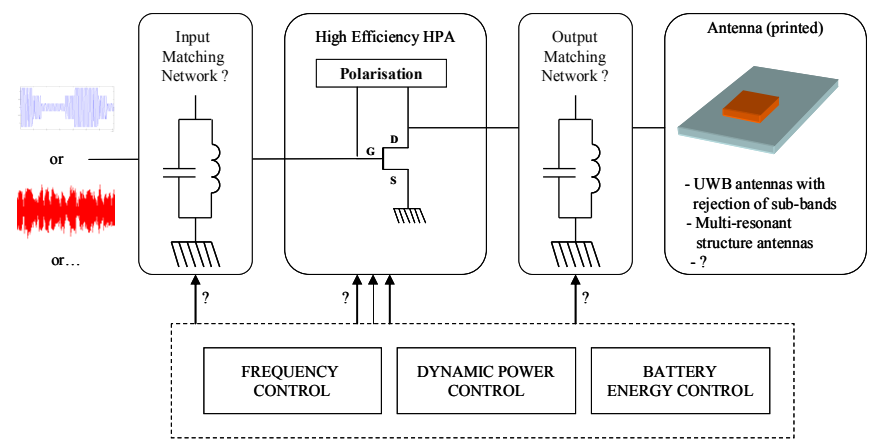

Figure 2 : front-end co-design principle for the multi-radio architecture

The idea is to design directly the output matching network of the switched PA with the antenna characteristics. As the flexibility implies the transmission in several bands between $900 \mathrm{MHz}$ and $6 \mathrm{GHz}$, the antenna should be designed with a multi-band characteristic. The front-end needs to be multi-bands, so it is preferable to design a band pass transfer function profile from the output of the transistor to the emitted wave (including the antenna). The goal is to control the optimum frequency of the HPA on the whole bandwidth while keeping efficiency and linearity (sinusoidal signal recovery) and if possible constant output power (to decorrelate this study with dynamic power control and amplitude restoration tasks). We focused on the famous class E HPA [1-2-3] and plan to tune the frequency by variation of parallel shunt capacitor. This can be accomplished with the insertion of RF MESFET switched or perhaps varactor diodes as will be discussed in the last part.

\section{B. Class E HPA topologies}

Designing of a class E HPA is based on several hypotheses for maximisation of the efficiency [1-2-3-5]. The switching of the transistor is often considered as ideal, which is an infinite to zero resistance. In the case of a MESFET transistor, we will introduce serial resistance $R_{D S}$ in parallel with the parasitic capacitor $\mathrm{C}_{\mathrm{DS}}$ at "on" state for the switch. At "off" state, the transistor may be abusively considered as $\mathrm{C}_{\mathrm{DS}}$ only for simplicity. This will results in sub-optimal efficiency in next part even if a parallel shunt capacitor is always present in class $\mathrm{E}$ topologies and can absorb this parasitic capacitance in theory. Goal of the high efficient switching is to present a inductive load to the output of the transistor in order to produce a better transient behaviour compared to ideal switch [1-2-3] : maximum voltage at zero current and maximum current at zero behaviour. The RF frequency $\omega_{\mathrm{RF}}$ of the design is so an un-tuned frequency of the output network, lower than the resonance frequency $\omega_{0}$ because the impedance is inductive. Any recovery between current and voltage at the drain (for a MESFET here) will cause dissipation power and so, a reduction of the drain efficiency. The class E HPA is often additively tuned with a $\mathrm{L}_{0}-\mathrm{C}_{0}$ serial resonance of infinite $\mathrm{Q}$ in the theoretical calculus. Taking into account the (finite) value of $Q$, results in an additional reduction of the drain efficiency. Indeed, the presence of $\mathrm{L}_{0}-\mathrm{C}_{0}$ will seriously complicate and lower the tuning possibilities of the class E HPA. To put it in a nutshell, the class E HPA consists in the design of an output network providing an inductive load to a switched transistor. There are mainly two possibilities as expressed in [2] and [3]. Including additional hypothesis such as the null of voltage derivate at the "off" state enables the definition of optimal values of the load resistance, shunt capacitor and the serial or parallel inductor.

The first topology (number 1) is presented as the classical serial inductor class E topology whose idealised equations were derived in [2] and are summarized by the figure 3 and its following equations.

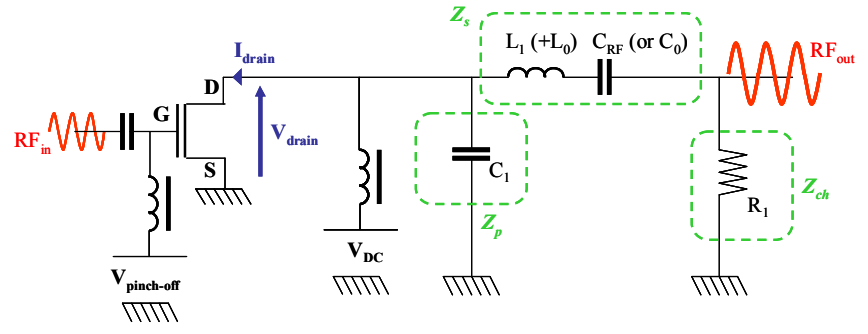

Figure 3 : First topology for the class E (serial inductor)

$$
\begin{aligned}
\mathrm{R}_{1} & =\frac{\mathrm{V}_{\mathrm{DC}}^{2}}{\mathrm{P}_{\mathrm{RF} \text { out }}} 0.5728 \\
\mathrm{~L}_{1} & =\frac{1.152 \mathrm{R}_{1}}{\omega_{\mathrm{RF}}}=\frac{\mathrm{x}_{1} \mathrm{R}_{1}}{\omega_{\mathrm{RF}}}=\frac{\mathrm{X}_{1}}{\omega_{\mathrm{RF}}} \\
\mathrm{C}_{1} & =\frac{0.1836}{\omega_{\mathrm{RF}} \mathrm{R}_{1}}=\frac{\mathrm{b}_{1}}{\omega_{\mathrm{RF}} \mathrm{R}_{1}}=\frac{\mathrm{B}_{1}}{\omega_{\mathrm{RF}}}
\end{aligned}
$$

As can be seen, the first topology employs a PI network and need a polarisation inductance for the drain voltage supply. Equivalent RF schematic is so composed of the RF switch (the transistor) and the PI network composed by $Z_{p}, Z_{s}$ and the load resistance $Z_{c h}\left(=R_{1}\right.$ here). At the $R F$ frequency of switching, $\mathrm{L}_{0}-\mathrm{C}_{0}$ can be avoided.

The second topology (number 2) is presented as the parallel tuned HPA by [3] and is more recent. Its design employs a parallel inductor in order to suppress the polarisation inductance. This topology is illustrated by the figure 4 and dedicated optimum values for the load resistance $\mathrm{R}_{2}$ and parallel capacitor $\mathrm{C}_{2}$ and inductor $\mathrm{L}_{2}$. As was the case for the first topology, the equivalent RF circuit consists in a switched transistor and a PI network with parallel, serial and load impedance. Of course the expression of $Z_{p}, Z_{s}$ and $Z_{c h}$ are dependant on the topology. 


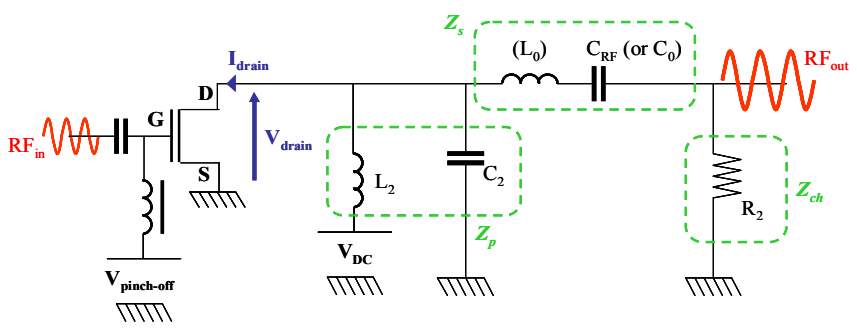

Figure 4 : Second topology for the class E (parallel inductor)

$$
\begin{aligned}
\mathrm{R}_{2} & =\frac{\mathrm{V}_{\mathrm{DC}}^{2}}{\mathrm{P}_{\mathrm{RFout}}} 1.365 \\
\mathrm{~L}_{2} & =\frac{0.732 \mathrm{R}_{2}}{\omega_{\mathrm{RF}}}=\frac{\mathrm{x}_{2} \mathrm{R}_{2}}{\omega_{\mathrm{RF}}}=\frac{\mathrm{X}_{2}}{\omega_{\mathrm{RF}}} \\
\mathrm{C}_{2} & =\frac{0.685}{\omega_{\mathrm{RF}} \mathrm{R}_{2}}=\frac{\mathrm{b}_{2}}{\omega_{\mathrm{RF}} \mathrm{R}_{2}}=\frac{\mathrm{B}_{2}}{\omega_{\mathrm{RF}}}
\end{aligned}
$$

As mentioned, both topologies for the class $\mathrm{E}$ can be electrically modelled by the network of figure 5 and calculation of transfer matrix $\underline{\underline{\mathbf{T}}}$ developed in function of $Z_{p}$, $Z_{\mathrm{s}}$ and $Z_{\mathrm{ch}}$. The expression of the output voltage $V_{R F}$ present on the load impedance can be derived. The $\mathrm{I}_{\text {out }}$ current defined by figure 5 is so equal to 0 as the load impedance has been included in the matrix. This model supposes that the transistor acts like a source of voltage $V_{\text {drain }}$ establishing a current $I_{\text {drain }}$ in the equivalent input impedance $Z_{\text {in }}$ of the circuit.
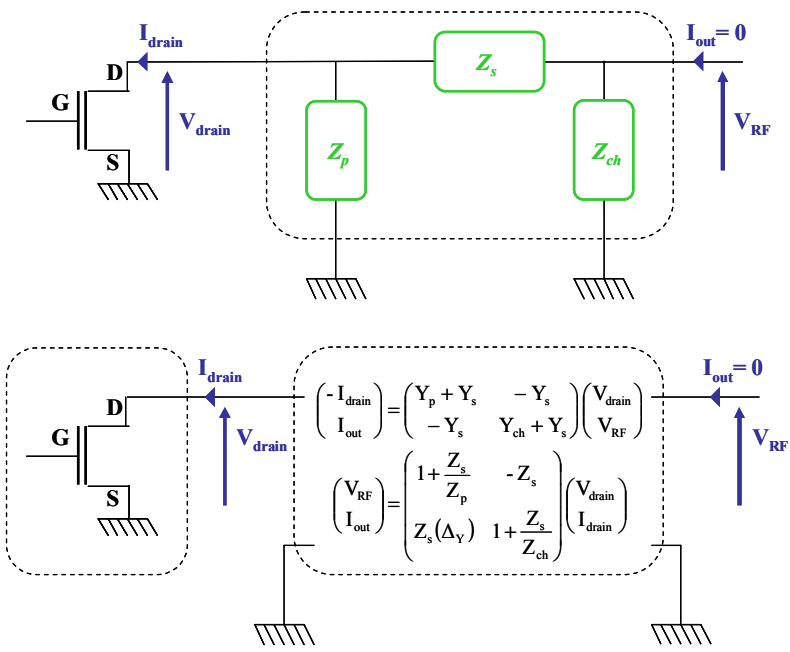

Figure 5 : Electrical model of both topologies for class E HPAs

A figure 5 analysis demonstrates the expression of the output voltage $\mathrm{V}_{\mathrm{RF}}$ to be independent of the load impedance... This is not correct if we forget the two others elements of the matrix that drives to an equation linking $\mathrm{V}_{\text {drain }}$ and $I_{\text {drain }}$ (due to the fact that $I_{\text {out }}=0$ ) that is no more than the expression of the input impedance of the network $\mathrm{Z}_{\text {in }}$. Both $\mathrm{V}_{\text {drain }}$ and $\mathrm{I}_{\text {drain }}$ are so highly affected by the impedance of the network, which means the transistor cannot be considered as a constant Thevenin or Norton equivalent source. The key parameter of the class E topology is so the theoretical value of the input impedance $Z_{\text {in }}$ that we will derive in cases 1 and 2 . Thanks to notations of figure 3 and 4 , we find the following results at the frequency of operation $\omega_{\mathrm{RF}}$ (switching frequency of the transistor) for the input impedances.

$$
\begin{gathered}
Z_{\text {in } 1}\left(\omega_{R F}\right)=R_{1} \frac{1+j\left(x_{1}-b_{1}\left(1+x_{1}^{2}\right)\right)}{1-2 x_{1} b_{1}+b_{1}^{2}\left(1+x_{1}^{2}\right)} \\
Z_{\text {in } 1}\left(\omega_{R F}\right)=R_{1}[1.5262+j 1.1064]=1.8849 R_{1} e^{j 36^{\circ}}
\end{gathered}
$$

$Z_{\text {in1 }}$ is the optimal impedance for the first topology (shunt capacitor with serial inductor) and $Z_{\text {in2 }}$ for the second one (shunt capacitor with parallel inductor).

$$
\begin{gathered}
Z_{\text {in } 2}\left(\omega_{R F}\right)=R_{2} \frac{x_{2}^{2}+j\left(x_{2}-b_{2} x_{2}^{2}\right)}{1-2 x_{2} b_{2}+x_{2}^{2}\left(1+b_{2}^{2}\right)} \\
Z_{\text {in } 2}\left(\omega_{R F}\right)=R_{2}[0.6831+j 0.4653]=0.8265 R_{2} e^{j 34^{\circ}}
\end{gathered}
$$

Knowing these important design considerations enable to simulate a realistic class E HPA, using a MESFET model, at an optimal RF frequency $\omega_{\mathrm{RF}}$ and then study the tuning possibility of the both topologies.

\section{III - SIMULATION RESULTS WITH A MESFET MODEL}

\section{A. Simulation of the two class E HPAs}

The two topologies are simulated under ADS software taking the same MESFET model with non zero values for $\mathrm{R}_{\mathrm{DS}}$ $(0.8 \mathrm{Ohm})$ and $\mathrm{C}_{\mathrm{DS}}(0.2 \mathrm{pF})$. Both Simulated PAs are designed for the same output power employing the same supply voltage. At this point, it is to notice an important difference in designs about optimal values of load resistances. The second topology employs a higher resistance than the first one at theoretically the same output power. This is expressed by the following relation between $R_{1}$ and $R_{2}$.

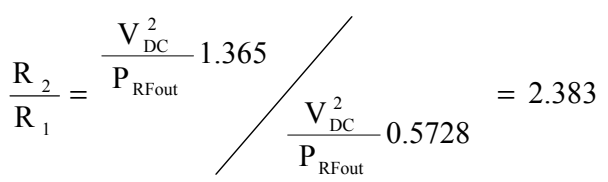

This is interesting for the PA designer because optimum load of PAs are often two small due to an important drive in current. Employing a higher resistance can reduce the $50 \mathrm{Ohms}$ matching task with the antenna (for simplicity we supposed here the antenna to match with 50 Ohms on subbands of the cognitive multi-radio standards). As predicted earlier, the input impedance as tuning characteristic due to inductive and capacitive parts and the resonance frequency $\omega_{0}$ is higher than the operating frequency $\omega_{\mathrm{RF}}$ because the load is designed to be inductive and not purely resistive. Cancelling the imaginary part of $Z_{\text {in }}$ compute the resonance values for topologies 1 and 2 and are summarized above.

$$
\begin{array}{ll}
\operatorname{Im}\left[Z_{\text {in } 1}\left(\omega_{01}\right)\right]=0 & \Rightarrow \omega_{01}=\sqrt{\frac{1}{L_{1} C_{1}}-\left(\frac{R_{1}}{L_{1}}\right)^{2}} \\
\operatorname{Im}\left[Z_{\text {in2 }}\left(\omega_{02}\right)\right]=0 & \Rightarrow \omega_{02}=\sqrt{\frac{1}{L_{2} C_{2}}}
\end{array}
$$


As is immediately seen, the two topologies act very differently. The tuning is dependant on the load resistance for the serial topology (number 1) and not for the parallel topology (2). In another point of view, the quality factor of the network is not varying with the shunt capacitor $\left(C_{2}\right)$ in the parallel topology (number 2). We will now observe the frequency dependence of the networks while trying to tune the HPA by variation of the shunt capacitor. This will be the only manner of tuning supposed for the moment because of technical possibilities (varactor diode or switched capacitor inserted).

\section{B. Tuning possibilities of the class $E$}

In order to illustrate the flexibility, the output network of the two class $\mathrm{E}$ are designed for $20 \mathrm{dBm}$ output power with a supply of $3 \mathrm{~V}$. The filtering tank $\mathrm{L}_{0} \mathrm{C}_{0}$ is lowered to a maximum of 10 because it adds a band-pass profile not compatible with tuning. HPA often needs a difficult low load resistance at such power and supply. Here the second topology has the advantage of higher load resistance, almost $50 \mathrm{Ohms}$. The tuning is done on the shunt capacitor, which is swept from $1 / 10$ to 10 times its nominal value. Results are summarized by the figure 6 .
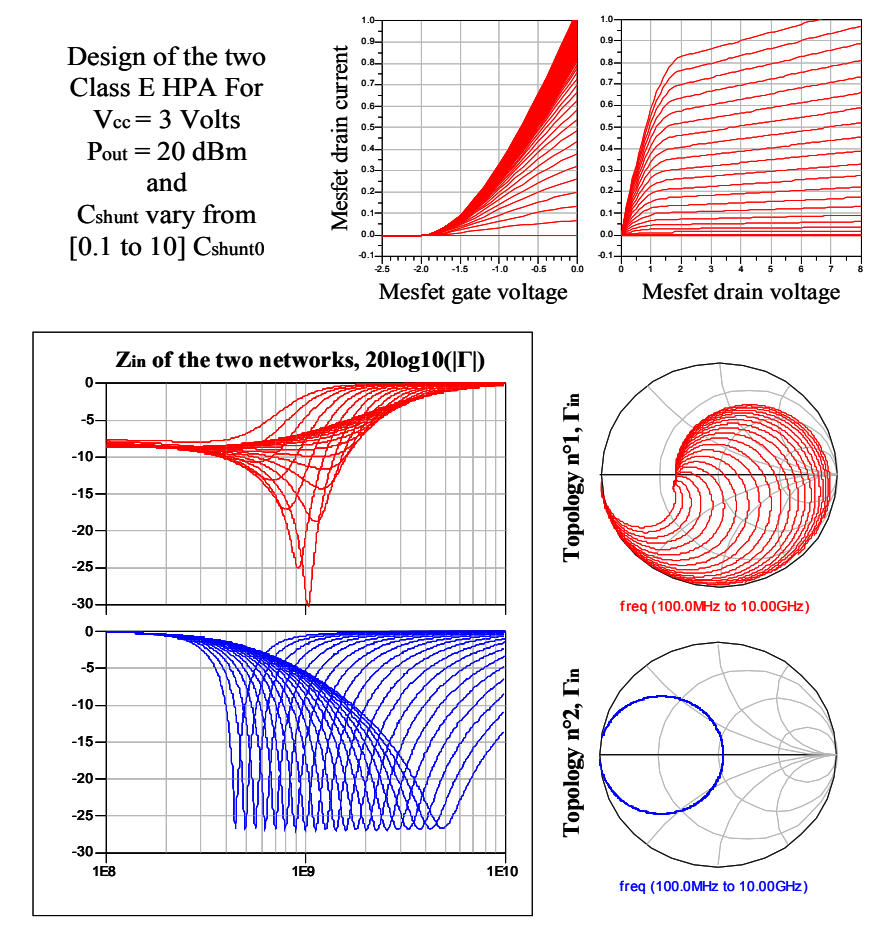

Figure 6 : Model of the MESFET (up). $Z_{\text {in }}$ with variations of the shunt capacitor value for the first (serial) and the second (parallel) topologies.

As can be seen on the figure 6 , the serial topology suffers from the frequency shifting, affecting the $Q$ of the resonance seen by the transistor. The parallel topology has the advantage of a regular shift in frequency that enables the tuning simulation even if the $\mathrm{Q}$ is dependant on the shunt capacitor and decreases with frequency. To conclude, it is more appropriate and simpler to use the second topology because the frequency is tune with modification of the shunt capacitor and resulting impedance can match the optimum impedance derived in previous part. For a tuned $\mathrm{C}_{\text {shunt }}$ in the second topology, it exists a frequency which provides the optimum impedance value of the class E operation.

The flexible HPA is so designed at this point with the parallel topology. We adapt the load resistor to $50 \mathrm{Ohms}$ in the absence of hypothesis about the antenna. Figure 7 provides the time evolution of the drain voltage and current in function of the addition (qualitative on this figure) of parallel capacitor $\mathrm{C}_{\mathrm{var}}$, to increase $\mathrm{C}_{\text {shunt }}$. The HPA provides more than $80 \%$ efficiency for $21 \mathrm{dBm}$ at $5 \mathrm{GHz}$. Keeping the same figure of merit in frequencies will be discussed in the following part.
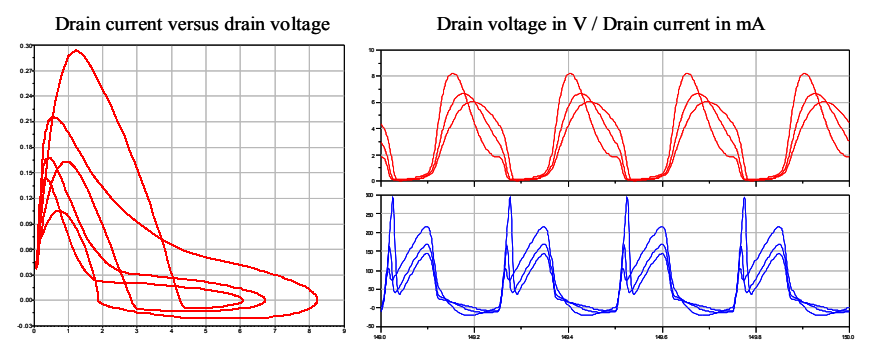

Figure 7 : Drain voltage and drain current of the class E HPA

\section{Efficiency results versus linearity}

We compute the efficiency, output power and spectrum of the output signal in order to compare the different simulations. The HPA needs to be high efficient and looking at the spectrum will reveals the linearity of the amplification.
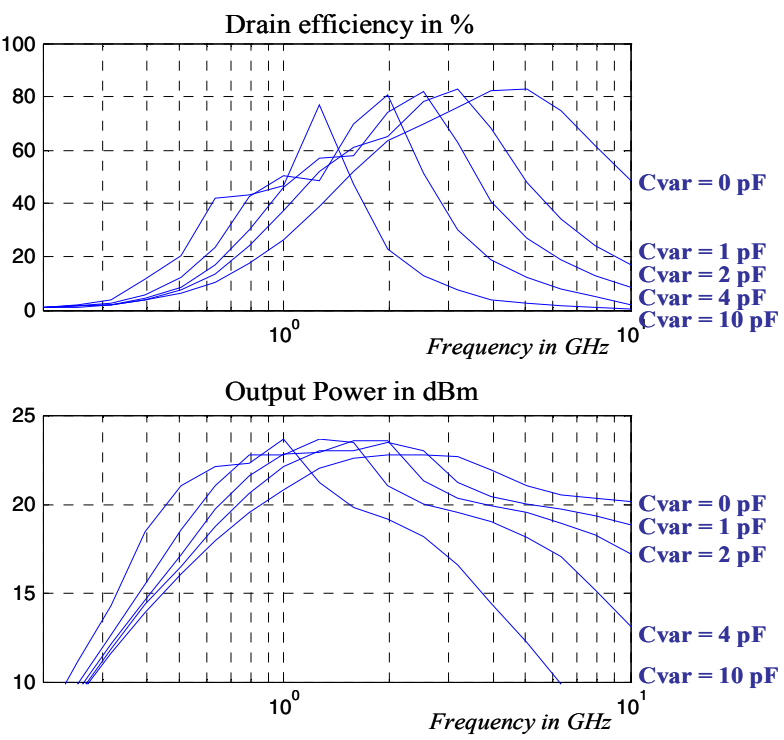

Figure 8 : Efficiency and output power in function of frequency and tuned by different additional shunt capacitor $C_{v a r}$.

Figure 8 reveals that it is possible to keep an efficient amplification of almost $80 \%$ if the shunt capacitance is increased. This is all the more interesting than the output power corresponding is not significantly modified, avoiding an, unwanted here, amplitude distortion. Increasing the capacitor can save up to $20 \%$ of drain efficiency. 

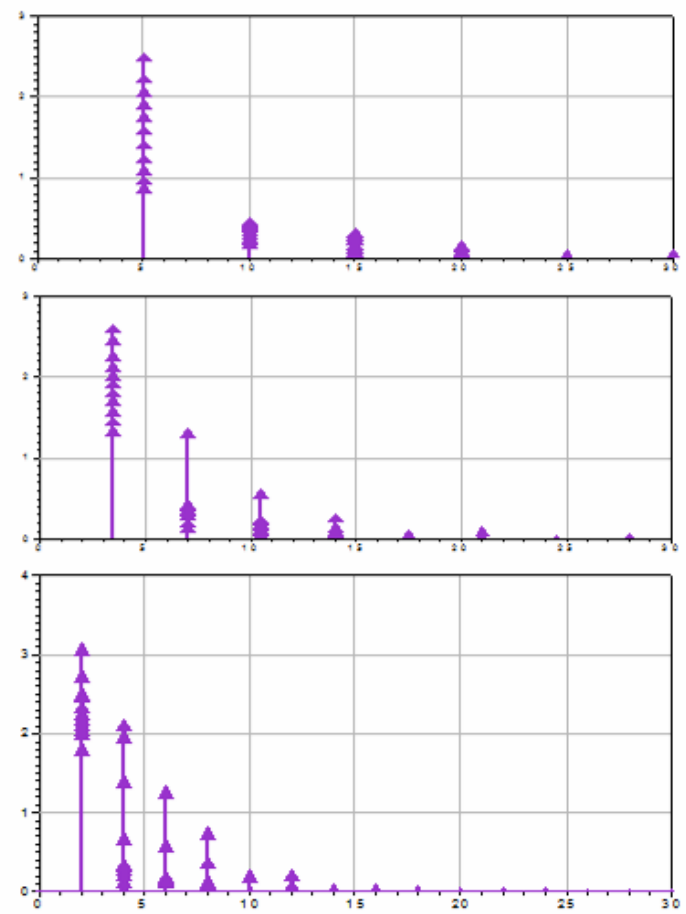

Figure 9 : output voltage spectrum at $1,3.5$ and $5 \mathrm{GHz}$

The linearity reported by figure 9 is not very good due to the absence of high selectivity filtering but the signal can be transmitted with some unavoidable distortion due to the harmonics. This is normal while considering the wanted flexibility characteristic. The linearity will be the limiting factor of this HPA in function of the modulation scheme. Another task will be to study the influence of the multi-band antenna impedance at the harmonics frequencies and the resulting linearity of the multi-radio front-end.

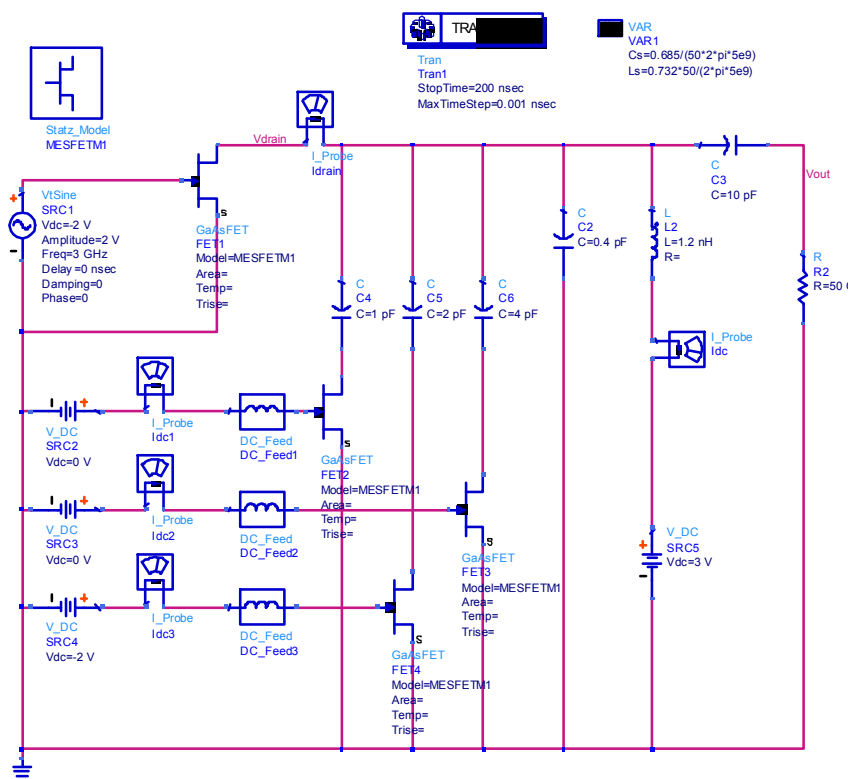

Figure 10 : class E HPA with switched additional shunt capacitors
We simulated the flexible HPA with realistic switched capacitor principle, as represented by figure 10 . The design shown enables an output power of $21 \mathrm{dBm}$ at $5 \mathrm{GHz}(80 \%)$ and can be easily modified for an output power of $23 \mathrm{dBm}$ at $1.5 \mathrm{GHz}(74 \%)$ if two "non RF power dissipating" transistors are switched. The same tuning is usually done in RF with varactor diodes and can also be reproduced.

\section{IV - PERSPECTIVES}

In this paper, we derived optimum equations for two class $\mathrm{E}$ topologies in order to produce a tuning possibility for the design of a flexible front end architecture, applied to cognitive multi-radio. The parallel topology shows several advantages: no chock inductance for the drain supply voltage, resonance tunability in function of the shunt capacitance, possibility of optimal frequency tuning and high load resistance: reducing (cancelling?) the problem of $50 \mathrm{Ohms}$ matching with the antenna. Simulations show interesting constant efficiency possibility at an almost constant output power. The linearity is not very good but is not a limiting factor and need to be studied in front of an impedance model of multi-band antenna. A deeper study of multi-radio modulations distortion due to the HPA impairment is also needed.

For the moment, the parallel topology with shunt capacitors offers an interesting perspective of high efficient RF front end flexibility for cognitive multi-radio. The frequency of operation can be set by voltage low consumption switches, compatible with a fast digital representation. One of the next goals will also be to study the dynamic control of the HPA output power.

\section{REFERENCES}

[1] N. Sokal, A. Sokal. Class E, A new Class of high efficiency Tuned single ended switching PAs. IEEE journal of Solid State Circuits, Vol. 10, No. 3, Juin 1975, pp 168-176.

[2] F. Raab. Idealised operation of the class E tuned PA. IEEE trans. on Circuits and Systems, Vol. 24, No. 12, 1977, pp 725-735.

[3] A. Grebennikov. Class E high efficiency PAs: Historical aspects and Future prospect. Applied Microwave and Wireless, Juillet 02, pp 64-71.

[4] A. Diet and al. EER architecture specifications for OFDM transmitter using a class E amplifier. IEEE Microwave and Wireless Component Letters, pp 389-391, V-14 I-8, Août 2004.

[5] A. Diet. Etude des architectures EER pour les émetteurs de radiocommunications numériques $3 \mathrm{G}$ et au delà. Rapport de thèse soutenue le 7 mars 2005, Université de Marne la Vallée.

[6] C. Berland and al. Transmitter architecture for non-constant Envelope Modulation. IEEE Transactions on circuits and systems II : Express Briefs, Vol. 53, $n^{\circ} 1$, January 2006. 